\title{
Isolation and functional characterization of cold-regulated promoters, by digitally identifying peach fruit cold-induced genes from a large EST dataset
}

\author{
Andrés Tittarelli1,2, Margarita Santiago ${ }^{1,2}$, Andrea Morales ${ }^{1,2}$, Lee A Meisel ${ }^{1,3}$ \\ and Herman Silva*1,2
}

Address: ${ }^{1}$ Millennium Nucleus in Plant Cell Biotechnology (MN-PCB), Santiago, Chile, ${ }^{2}$ Plant Functional Genomics \& Bioinformatics Lab, Universidad Andrés Bello, Santiago, Chile and ${ }^{3}$ Centro de Biotecnología Vegetal, Universidad Andrés Bello, Santiago, Chile

Email: Andrés Tittarelli - tittarelli@gmail.com; Margarita Santiago - santiago_margarita@yahoo.es;

Andrea Morales - andreamoralesa@gmail.com; Lee A Meisel - lmeisel@gmail.com; Herman Silva* - herman.silva@gmail.com

* Corresponding author

Published: 22 September 2009

BMC Plant Biology 2009, 9:121 doi:10.1 186/147|-2229-9-121
Received: 9 February 2009

Accepted: 22 September 2009

This article is available from: http://www.biomedcentral.com/I47I-2229/9//2I

(c) 2009 Tittarelli et al; licensee BioMed Central Ltd.

This is an Open Access article distributed under the terms of the Creative Commons Attribution License (http://creativecommons.org/licenses/by/2.0), which permits unrestricted use, distribution, and reproduction in any medium, provided the original work is properly cited.

\begin{abstract}
Background: Cold acclimation is the process by which plants adapt to the low, non freezing temperatures that naturally occur during late autumn or early winter. This process enables the plants to resist the freezing temperatures of winter. Temperatures similar to those associated with cold acclimation are also used by the fruit industry to delay fruit ripening in peaches. However, peaches that are subjected to long periods of cold storage may develop chilling injury symptoms (woolliness and internal breakdown). In order to better understand the relationship between cold acclimation and chilling injury in peaches, we isolated and functionally characterized cold-regulated promoters from cold-inducible genes identified by digitally analyzing a large EST dataset.
\end{abstract}

Results: Digital expression analyses of EST datasets, revealed 164 cold-induced peach genes, several of which show similarities to genes associated with cold acclimation and cold stress responses. The promoters of three of these cold-inducible genes (Ppbecl, Ppxero2 and Ppthal) were fused to the GUS reporter gene and characterized for cold-inducibility using both transient transformation assays in peach fruits (in fruta) and stable transformation in Arabidopsis thaliana. These assays demonstrate that the promoter Ppthal is not cold-inducible, whereas the Ppbecl and Ppxero2 promoter constructs are cold-inducible.

Conclusion: This work demonstrates that during cold storage, peach fruits differentially express genes that are associated with cold acclimation. Functional characterization of these promoters in transient transformation assays in fruta as well as stable transformation in Arabidopsis, demonstrate that the isolated $\mathrm{Ppbecl}$ and Ppxero2 promoters are cold-inducible promoters, whereas the isolated Ppthal promoter is not cold-inducible. Additionally, the cold-inducible activity of the Ppbecl and Ppxero2 promoters suggest that there is a conserved heterologous cold-inducible regulation of these promoters in peach and Arabidopsis. These results reveal that digital expression analyses may be used in non-model species to identify candidate genes whose promoters are differentially expressed in response to exogenous stimuli. 


\section{Background}

Cold temperature is an environmental factor that plays an important role in plant growth and development. Temperate plants have developed mechanisms to adapt to periods of low non-freezing temperatures, enabling these plants to survive subsequent freezing temperatures. This process is called cold acclimation [1]. Cold acclimation is a complex process that involves physiological, biochemical and molecular modifications [2-4]. Hundreds of genes have been shown to have altered expression levels during cold acclimation [5]. These alterations enable the plant to withstand freezing by creating a chronic response that protects the integrity of the cellular membranes, enhances anti-oxidative mechanisms and accumulates molecular cryoprotectants [6].

Under normal conditions, cold acclimation is initiated by the cold temperatures of late fall and early winter, when fruit trees lack fruits. Similar cold temperatures have been used in the fruit industry to store fruits for prolonged periods of time. These temperatures inhibit fruit ripening, thereby extending fruit postharvest life. Despite the benefits, peaches that are subjected to long periods of cold storage can develop chilling injury symptoms (i.e. woolliness and internal breakdown) which reduce the postharvest quality of these fruits and results in significant economical losses [7-9].

Most of the efforts directed towards understanding the molecular basis of cold acclimation have been performed in the model plant $A$. thaliana [1-4]. Little is known about what occurs under low, non-freezing temperatures in fruits or fruit trees. Since chilling injury occurs in fruits that have undergone long-term cold storage, perhaps cold acclimation processes are associated with this injury. A better understanding of cold acclimation and coldresponsive genes in peach trees and fruits may provide clues about the association of cold acclimation and chilling injury.

Several transcription factors associated with cold acclimation have been shown to regulate the expression of coldinducible genes containing conserved ABRE (abscisic acid response elements) and/or DRE (dehydration-responsive) elements in their promoters [10-13]. The regulation of cold-inducible promoters in peaches may be mediated by the interaction between promoters containing these types of cis-elements and orthologous transcription factors. However, the identification and functional characterization of these types of promoters in fruit trees is lacking.

We have demonstrated previously that there is a conserved heterologous regulation of the wheat putative high-affinity Pi transporter, TaPT2 in both monocots (wheat) and dicots (Arabidopsis) [14]. These findings demonstrate that Arabidopsis may be used as a heterologous system to test the functionality of promoters. However, this type of heterologous regulation may not exist for all promoters and may not be conserved among all plant species. An alternative to functional analyses in heterologous systems is transient transformation of fruits using agro-infiltration. Agro-infiltration of fruits have been performed to test the activity of the 35S CaMV promoter fused to reporter genes such as GUS or luciferase in tomatoes, apples, pears, peaches, strawberries and oranges $[15,16]$. However, to our knowledge, it has not been used to determine the activity of cold-inducible promoters within the fruit (in fruta).

To identify cold-responsive genes expressed in peach fruits, digital expression analyses of ESTs from fruits exposed to four different postharvest conditions were analyzed [17]. Isolation of the promoter regions of three genes highly expressed in fruits that have undergone longterm cold storage, allowed us to identify common regulatory elements present in these promoters. Functional characterization of these promoters (stably in A. thaliana and transiently in peach fruits) demonstrates that these are peach cold-inducible promoters and that there is a conserved heterologous regulation of these promoters in peach and Arabidopsis.

\section{Methods \\ Digital expression analyses}

We have previously described the contigs used in this work [17]. The ESTs that make up these contigs represent transcripts from peach fruit mesocarp at four different postharvest conditions. The post-harvest conditions include: fruits processed in a packing plant (E1: non-ripe; no long term cold storage); packing followed by a shelflife at $20^{\circ} \mathrm{C}$ for 2-6 days (E2: Ripe; no long term cold storage; juicy fruits); packing followed by cold storage at $4{ }^{\circ} \mathrm{C}$ for 21 days (E3: non-ripe; long term cold storage) and packing followed by cold storage at $4^{\circ} \mathrm{C}$ for 21 days and shelf-life at $20^{\circ} \mathrm{C}$ for 2-6 days (E4: Ripe; long term cold storage; woolly fruits).

As we described in Vizoso et al [17], the contigs that represent differentially expressed genes were identified using the Winflat program that submits the sequence data to a rigorous statistical analysis described by Audic and Claverie [18] http://igs-server.cnrs-mrs.fr. This analysis calculates the probability that a gene is equally expressed in two different conditions by observing the distribution of tag counts (number of ESTs). Therefore, small probability values ( $p$-values) are associated with non-symmetrical distributions, characteristic of differentially expressed genes [18,19]. 
To analyze the co-expression of differentially expressed genes, contigs were clustered using the Pearson linear correlation coefficient $[19,20]$. Briefly, contigs with at least five ESTs were selected to make the expression profile matrix, which consisted of 1,402 rows (the contigs) and 4 columns (four cDNA libraries). The similarity between clusters and libraries was estimated using an un-centered Pearson's correlation coefficient in the Cluster 3.0 program [20]http://rana.lbl.gov/EisenSoftware.htm. Pearson correlation coefficients $>0.85$ (zero values indicate no association and a coefficient equal to 1 indicate a fully correlated pattern) are indicated by an asterisk in Additional File 1. Dendrograms were constructed from the pair wise distances using the UPGMA algorithm. The results were visualized and analyzed using the Java TreeView program http://itreeview.sourceforge.net.

Gene Ontology molecular function and biological process annotations of the contigs are described in Vizoso et al [17]. Each annotation and contig assembly was manually corrected, when necessary.

\section{mRNA isolation and reverse transcriptase (RT)-PCR}

The kit Oligotex ${ }^{\mathrm{TM}}$ mRNA Spin-Column (Qiagen, New York, USA) was used to purify mRNA. The mRNA was purified from pools of total RNA obtained from peach fruit mesocarp ( $\mathrm{O}^{\prime} H e n r y$ var.) representing the stages E1, $\mathrm{E} 2, \mathrm{E} 3$ and $\mathrm{E} 4$ as described previously $[17,21]$. The mRNA was quantified using the Poly (A) mRNA Detection System $^{\text {Ty }}$ (Promega, Madison, USA). First strand cDNA was synthesized from $5 \mathrm{ng}$ of the mRNA in a $20 \mu \mathrm{l}$ final volume. The reaction mix was prepared using the ImProm$\mathrm{II}^{\mathrm{TM}}$ reverse Transcription System (Promega, Madison, USA) and anchored oligo (dT) of 18-mers, according to the manufacturer's instructions. As an internal control for normalization, heterologous mRNA (1.2 kb mRNA coding for Kanamycin) was added to each mRNA sample. To control for genomic DNA contamination, PCR amplification was performed on template RNA that was not reverse transcribed. To confirm that the amplified fragments correspond to the cDNAs of interest, these fragments were cloned in pBluescript and sequenced (Macrogen, Korea). The primer sequences used to amplify the internal regions of the basic endochitinase Ppbec1 (BEC226F and BEC576R), dehydrin Ppxero2 (DX-82F and DX176R), thaumatin Pptha1 (THA30F and THA382R), lipoxygenase Pplox1 (LOX982F and LOX1267R) and the actin Ppact7 (ACT-F and ACT-R) genes are shown in Table 1. Primers used to amplify a $323 \mathrm{bp}$ fragment of the cDNA from the Kanamycin mRNA control are: "Upstream Control Primer" (5'-gCCATTCTCACCggATTCAgTCgTC-3') and "Downstream Control Primer" (5'-AgCCgCCgTCCCgTCAAgTCAg-3'). PCR reactions were performed by diluting the cDNAs a 100 fold and using $1 \mu$ of each dilution as a template in a final reaction volume of $20 \mu \mathrm{l}$, containing $0.5 \mu \mathrm{M}$ primers; $0.2 \mathrm{mM}$ dNTPs; $1.5 \mathrm{mM} \mathrm{MgCl}_{2}$; $5 \mathrm{U}$ Taq polymerase and $1 \times$ buffer. The PCR conditions were: $93^{\circ} \mathrm{C}$ for $5 \mathrm{~min}$ and then a variable number of cycles $(26$ to 34 ) at $93^{\circ} \mathrm{C}$ for $30 \mathrm{sec}, 1 \mathrm{~min}$ at $55^{\circ} \mathrm{C}$, and $1 \mathrm{~min}$ at

Table I: Primers used in this study

\begin{tabular}{|c|c|c|}
\hline Primer & Sequence $\left(5^{\prime} \rightarrow 3^{\prime}\right)$ & Method \\
\hline BEC226F & gTCAgCAgCgTCgTTAgCTC & RT-PCR \\
\hline BEC576R & gAgTTggATgggTCСТCTgC & \\
\hline $\mathrm{DX}-82 \mathrm{~F}$ & CCAAACCAAAgCCAgTTTCATTCA & \\
\hline$D \times 176 R$ & CCAggTTTTgTATgAgTgCCgTA & \\
\hline THA30F & ACCTTggCCATCСТСТTCTT & \\
\hline THA382R & AgAAATCTTgACCCCCgTTC & \\
\hline LOX982F & AAggAgCTCTTgACgTTggA & \\
\hline LOXI267R & TgCTAACAggTgggAAAACC & \\
\hline ACT-F & CCTTCCAgCAgATgTggATT & \\
\hline ACT-R & AgATTAggCAAggCgAggAT & \\
\hline BEC87-GSPI & TgCATTTCCAgCTTgCCTCCCACATTg & Genome Walker \\
\hline BEC55-GSP2 & CTgAgATCCCTAACAgCAAAgCTAgggATA & \\
\hline DX85-GSPI & ACCggTTCCggTggTggTgTgATgAACC & \\
\hline DX46-GSP2 & ACTCATCAgTCTTAgTAggCTCgggTgTT & \\
\hline THA82-GSPI & TgATTTTAgCTgCATgTgCACCTgAgAA & \\
\hline THA-I-GSP2 & CgTCATggAAATgTCTTAATTggCTTgCTg & \\
\hline LOXIOI-GSPI & gAAgAAAACAAATTgggAggAggAgAA & \\
\hline LOX63-GSP2 & gCgTgTTCCAAAgAACACAATTCAgTgCCTT & \\
\hline BEC-32BamHI & ggATCCTgATCTgTggATTgggTTTCgTgg & Subcloning promoters \\
\hline DX24BamHI & ggATCCgggTgTTgAACCAAAATgCgCCATT & \\
\hline
\end{tabular}


$72^{\circ} \mathrm{C}$. The PCR reaction was with a final step at $72^{\circ} \mathrm{C}$ for $10 \mathrm{~min}$.

\section{Cloning of the promoters}

Genomic DNA was isolated from peach leaves (Prunus persica var. persica (L.) Batch cv. O'Henry) as described in Manubens et al [22]. The Universal Genome Walker ${ }^{\mathrm{TM}} \mathrm{Kit}$ (Clontech Laboratories, Inc., Palo Alto, CA, USA) was used to isolate the promoters regions of Ppbec1, Ppxero2, Pptha1 and Pplox1. The isolated genomic DNA was digested with four restriction enzymes (EcoRV, PvuII, SspI, and $M l s \mathrm{I}$ ). DNA fragments containing adaptors at both ends were used as a template for amplifying the promoter regions. GSP1 and GSP2 gene specific primers were designed to isolate the promoters (Table 1). For the first group of PCR reactions, a specific adaptor primer (AP1, 5'ggATCCTAATACgACTCACTATAgggC-3') and the GSP1 primers specific for each gene were used. The final primer concentration in the PCR reaction was $0.2 \mu \mathrm{M}$ in a final volume of $50 \mu \mathrm{L}$. Manual Hot Start was performed using $5 \mathrm{U}$ of the Synergy DNA polymerase (Genecraft, Münster, Germany). The conditions for this first round of amplifications was: 1 cycle at $93^{\circ} \mathrm{C}$ for $10 \mathrm{~min}, 7$ cycles of $93^{\circ} \mathrm{C}$ for $30 \mathrm{sec}, 72^{\circ} \mathrm{C}$ for $15 \mathrm{~min}$, followed by 37 cycles of $93^{\circ} \mathrm{C}$ for $30 \mathrm{sec}, 67^{\circ} \mathrm{C}$ for $15 \mathrm{~min}$. For the nested PCR, the specific adaptor primer 2 (AP2, 5'-ACTATAgggCACgCgTggT$\left.3^{\prime}\right)$ and the gene specific GSP2 primers were used. As a DNA template in these reactions, $1 \mu \mathrm{L}$ of a 50 fold dilution of end-product of the first round of amplifications was used. The conditions for the second round of amplification were: 1 cycle at $93^{\circ} \mathrm{C}$ for $10 \mathrm{~min}, 5$ cycles $(7$ cycles in the case of Ppxero2) of $93^{\circ} \mathrm{C}$ for $30 \mathrm{sec}, 72^{\circ} \mathrm{C}$ for 15 min, followed by 20 cycles (30 cycles in the case of Ppxero2) of $93^{\circ} \mathrm{C}$ for $30 \mathrm{sec}, 67^{\circ} \mathrm{C}$ for $15 \mathrm{~min}$. The amplified products were cloned in pGEM-T vector and sequenced (Macrogen, Korea). The Ppbec1 and Ppxero2 promoters were subsequently amplified from the pGEM$\mathrm{T}$ clones using the AP2 and BEC-32BamHI or DX24BamHI primers, respectively (Table 1 ). The products of this amplification were also cloned in the PGEM-T vector and re-sequenced (Macrogen, Korea). The promoter fragments were extracted from the pGEM-T vector (including the Pptha1 promoter), with a BamHI-SalI sequential digestion, and transcriptionally fused to the uidA reporter gene in the promoterless binary vector pBI101.1 [23]. The binary vector was introduced into $A$. tumefaciens (GV3101) for subsequent Arabidopsis and peach fruit transformations.

\section{Promoter sequences analysis}

Analysis of putative transcription factor binding sites was carried out using the database PLACE http:// www.dna.affrc.go.jp/htdocs/PLACE/[24] coupled with visual analyses. To identify predicted conserved motifs, the promoter sequences were analyzed using the YMF 3.0 program [25] http://wingless.cs.washington.edu/YMF/ YMFWeb/YMFInput.pl. Only the statistically significant motifs ( $\mathrm{Z}$ score value $>6.5$ ) were selected [26].

Growth, transformation and cold treatments of $A$. thaliana Wild-type and transgenic $A$. thaliana (ecotype Columbia) were grown in a mixture of soil-vermiculite (3:1) in a growth chamber with a $16-\mathrm{h}$ light cycle $\left(140 \mu \mathrm{mol} \mathrm{m}^{-2} \mathrm{~s}^{-}\right.$ $\left.{ }^{1}\right)$ at $22^{\circ} \mathrm{C}$. Alternatively, seeds were surface sterilized as described in Gonzalez et al [27], plated on MurashigeSkoog $(1 \times$ MS) media containing $0.8 \%$ agar, $0.1 \%$ sucrose and $50 \mathrm{mg} / \mathrm{l}$ Kanamycin for transgenic lines and grown under the same conditions as the soil-grown plants.

Transgenic Arabidopsis was obtained by using the GV3101 A. tumefaciens-mediated floral dip method [28]. A. tumefaciens previously transformed with the binary vector pBI101.3 harboring the promoter::uidA fusions: Ppbec1::uidA (PBIPpbec1); Ppxero2::uidA (pBIPpxero2); Pptha1::uidA (pBIPptha1), or the control vectors pBI121 (containing the 35S CaMV promoter) and pBI101.3 (promoterless), were used. In cold treatments, $T_{3}$ homozygous transgenic Arabidopsis seedlings were grown on plates containing $1 \times$ MS media, $0.8 \%$ agar, and $0.1 \%$ sucrose in a growth chamber with a 16 -h light cycle $\left(140 \mu \mathrm{mol} \mathrm{m}^{-2} \mathrm{~s}^{-}\right.$ ${ }^{1}$ ) at $24^{\circ} \mathrm{C}$ for two weeks, and then transferred to $4^{\circ} \mathrm{C}$ for 7 days. A minimum of three independent transgenic lines were used for each construct.

Peach fruit transient transformation and cold treatments A. tumefaciens transformed with the vectors pBIPpbec1, pBIPpxero2, pBIPptha1, pBI121 or pBI101.3 were grown in LB medium supplemented with Kanamycin $(100 \mu \mathrm{g} /$ $\mathrm{ml})$, Rifampicin $(10 \mu \mathrm{g} / \mathrm{ml})$ and Gentamycin $(100 \mu \mathrm{g} /$ $\mathrm{ml}$ ). The cultures were grown for two days at $28^{\circ} \mathrm{C}$ until they reached an $\mathrm{OD}_{600}$ between 0.6 and 0.8 . The culture was then centrifuged and the pellet re-suspended in MMA medium (1× MS, MES $10 \mathrm{mM}$ (pH 5.6), $20 \mathrm{~g} / \mathrm{l}$ sucrose, and $200 \mu \mathrm{M}$ acetosyringone) to reach an $\mathrm{OD}_{600}$ of 2.4 . Approximately $0.7 \mathrm{~mL}$ of this bacterial suspension was used to infiltrate mature fruits from O'Henry, Elegant Lady and Florida King varieties of peach as described by Spolaore et al [15].

To analyze the promoter activity at $20^{\circ} \mathrm{C}$, the fruits infiltrated with the different constructs, were stored in a dark growth chamber for five days. To analyze the cold-responsive promoter activity, the infiltrated fruits were stored 2 days post-infiltration (dpi) in a dark growth chamber at $4{ }^{\circ} \mathrm{C}$ for 10 days. After the growth chamber incubation time, the infiltrated region of the fruit was extracted with a cork bore and stained for GUS activity as described by Tittarelli et al [14]. 


\section{GUS activity measurement}

Histochemical staining of Arabidopsis seedlings for $\beta$-glucuronidase (GUS) activity was performed as described by Jefferson et al [23], with the following modifications: transgenic Arabidopsis seedlings used in the cold-treatments described earlier were vacuum infiltrated in $50 \mathrm{mM}$ $\mathrm{NaH}_{2} \mathrm{PO}_{4}, \mathrm{pH} 7.0 ; 0.1 \mathrm{mM}$ X-Gluc; $10 \mathrm{mM}$ EDTA and $0.1 \%$ Triton $\mathrm{X}-100$. These samples were incubated in the dark at $37^{\circ} \mathrm{C}$ for 24-72 h. Samples that did not develop color after $72 \mathrm{~h}$ were considered negative for GUS activity. Plant material was subsequently fixed in $0.04 \%$ formaldehyde, $0.04 \%$ acetic acid and $0.285 \%$ ethanol for $30 \mathrm{~min}$, followed by an ethanol dilution series to remove chlorophyll from the plant tissue (70\% ethanol for $1 \mathrm{~h}, 100 \%$ ethanol for $1 \mathrm{~h}, 70 \%$ ethanol for $1 \mathrm{~h}$ and distilled water).

Slices $(2 \mathrm{~mm})$ of transiently transformed peaches were imbibed in the GUS staining solution $\left(0.72 \mathrm{M} \mathrm{K}_{2} \mathrm{HPO}_{4}\right.$; $0.17 \mathrm{M} \mathrm{KH}_{2} \mathrm{PO}_{4} ; 0.5 \mathrm{mM} \mathrm{K}_{3} \mathrm{Fe}(\mathrm{CN})_{6} ; 0.5 \mathrm{mM} \mathrm{K}_{4} \mathrm{Fe}(\mathrm{CN})_{6}$; $1 \times$ Triton X-100; $12.7 \mathrm{mM}$ EDTA; 20\% (v/v) methanol and $0.5 \mathrm{mM}$ X-Gluc) [15]. Samples were vacuum-infiltrated for $30 \mathrm{~min}$ at room-temperature and then incubated overnight at $37^{\circ} \mathrm{C}$. Fluorometric GUS assays were performed as described by Jefferson et al [23]. The Arabidopsis seedlings were ground in a mortar using liquid nitrogen, and the tissue powder was transferred to a microtube. One $\mathrm{ml}$ of the extraction buffer $(50 \mathrm{mM}$ $\mathrm{NaH}_{2} \mathrm{PO}_{4}$, pH 7.0; 1 mM EDTA; 0.1\% Triton X-100; 0.1\% $(\mathrm{w} / \mathrm{v})$ sodium laurylsarcosine and $5 \mathrm{mM}$ dithiothreitol) was added. Samples were centrifuged for $10 \mathrm{~min}$ at 12,000 $\mathrm{g}$ at $4{ }^{\circ} \mathrm{C}$ and the supernatant was transferred to a new microtube. The fluorogenic reaction was carried out in 2 ml volume containing $1 \mathrm{mM} 4$-methyl umbelliferyl glucuronide (MUG) in an extraction buffer supplemented with a $50 \mu \mathrm{L}$ aliquot of the protein extract supernatants. The protein quantity of the sample extracts was determined as described previously [29], using bovine serum albumin (BSA) as a standard.

\section{Results \\ Identification of peach cold-regulated genes by digital expression analyses of EST datasets}

Coordinated gene expression analyses of peach fruit ESTs datasets revealed 10 major hierarchical clusters (Additional File 1), containing unique contigs. We identified 164 contigs with preferential expression in fruits stored at $4{ }^{\circ} \mathrm{C}$ (E3: non-ripe; long term cold storage). Table 2 contains a complete list of these contigs together with their annotations, GO biological process annotations and the origin of the ESTs in each contig. Contigs with statistically differential expression, in E3 compared to the other stages are also indicated.

Approximately 95\% of the 164 cold-induced peach genes share significant identity with sequences in Arabidopsis, suggesting that these may be putative orthologs. The putative Arabidopsis orthologs that are induced or repressed by cold, based on ColdArrayDB analyses http://cold.stan ford.edu/cold/cgi-bin/data.cgi are shown in Table 2. Only 29 contigs ( $18 \%$ of the 164 cold-induced genes) share significant sequence identity with genes of unknown function. Approximately $38 \%$ of these contigs (11 contigs) share significant sequence identity with plant gene sequences annotated as expressed proteins. Six of the contigs with unknown function do not share sequence identity with any sequences in the public databases, suggesting that these are novel genes.

Annotation frequency comparative analyses of coldinduced (164 contigs), cold-repressed (138 contigs) or contigs unrelated to cold (1,238 contigs), revealed an overrepresentation of stress response genes and an underrepresentation of genes related to energy metabolism in fruits that were stored in the cold (Figure 1). Among the genes related to stress response we identified four contigs that are similar to thaumatin-like proteins: C1708, C2177, C2317 and C2147 (98\%, 99\%, 98\% and 93\% amino acid identity with $P$. persica thaumatin-like protein 1 precursor, respectively, GenBank accession number: P83332). Three of the stress response genes are similar to chitinases: C910 (76\% amino acid identity with Malus domestica class III acidic endochitinase, GenBank accession number: ABC47924); C2131 (74\% amino acid identity with Galega orientalis class Ib basic endochitinase, GenBank accession number: AAP03087) and C2441 (72\% amino acid identity with $A$. thaliana class IV chitinase, GenBank accession number: NP 191010). Two of the stress response genes are similar to dehydrins: C254 (97\% amino acid identity with P. persica Ppdhn1, GenBank accession number: AAC49658) and C304, 100\% amino acid identity with $P$. persica type II SK2 dehydrin Ppdhn3 (Genbank accession number: $\underline{\text { AAZ83586). }}$.

Cold-induced expression of Ppbecl, Ppxero2 and Ppthal We evaluated the expression levels of three cold-induced candidate genes by RT-PCR: a basic endochitinase (C2131, Ppbec1), a dehydrin (C254, Ppxero2) and a thaumatin-like protein (C2317, Pptha1). These genes were chosen due to the high number of ESTs in cold-stored fruits (E3), as revealed by the digital expression analyses (Figure 2). The expression level of a contig similar to lipoxygenase (C3336, Pplox1) that does not express preferentially in cold stored fruits (E3) as well as the expression level of a contig (C407, Ppact7) that does not significantly change expression under the different postharvest conditions, were analyzed (Figure 2). Interestingly, all five genes analyzed showed an expression pattern significantly similar to the ones predicted by the digital expression analyses (Figure 2). The genes Ppbec1, Ppxero2 and Pptha1 have an increased expression in cold- 
Table 2: Putative function of 164 genes preferentially expressed in cold stored peach fruits.

\begin{tabular}{|c|c|c|c|c|}
\hline Contig & E3 & $\mathrm{EI}+\mathrm{E} 2+\mathrm{E} 4$ & AC test ${ }^{\prime}$ & Putative Function;Arabidopsis ortholog2 \\
\hline \multicolumn{5}{|c|}{ Biological process unknown (GO:0000004) } \\
\hline $\mathrm{C} 517$ & 10 & 6 & E4 & NC domain-containing protein (located in mitochondrion); At5g06370 \\
\hline C675 & 12 & 4 & E2; E4 & Expressed protein; At3g03870 $\downarrow$ \\
\hline C774* & 11 & 4 & E2; E4 & Novel gene \\
\hline C2089 & 20 & 0 & $\mathrm{EI} ; \mathrm{E} 2 ; \mathrm{E} 4$ & Expressed protein (located in endomembrane system); At5g64820 \\
\hline $\mathrm{C} 2112$ & 31 & 2 & $\mathrm{EI} ; \mathrm{E} 2 ; \mathrm{E} 4$ & Cupin family protein (nutrient reservoir activity); At Ig07750 \\
\hline $\mathrm{C} 2139$ & 12 & 0 & $\mathrm{EI} ; \mathrm{E} 2 ; \mathrm{E} 4$ & Novel gene \\
\hline C4065 & 13 & 8 & E2 & Expressed protein; At5g52870 $\uparrow$ \\
\hline $\mathrm{C} 273$ & 5 & 2 & & Expressed protein; At5g24660 $\downarrow$ \\
\hline C477 & 7 & 6 & & Expressed protein (located in endomembrane system); At5g645 I $0 \downarrow$ \\
\hline $\mathrm{Cl} 207^{*}$ & 8 & 7 & & Novel gene \\
\hline C2134 & 3 & 2 & & Expressed protein; At lg71080 \\
\hline $\mathrm{C} 2148$ & 4 & I & & Novel gene \\
\hline $\mathrm{C} 2155$ & 4 & 1 & & Expressed protein; At5gII730 \\
\hline $\mathrm{C} 2167$ & 3 & 2 & & RWD domain-containing protein; At $\lg 51730$ \\
\hline $\mathrm{C} 2173$ & 7 & 1 & & Expressed protein (located in mitochondrion);At5g60680个 \\
\hline $\mathrm{C} 2193$ & 3 & 2 & & Novel gene \\
\hline $\mathrm{C} 2211$ & 8 & 1 & & Ankyrin repeat family protein (protein binding); At2g28840 \\
\hline $\mathrm{C} 2241$ & 6 & 2 & & Expressed protein (located in mitochondrion); At5g5 I040 \\
\hline $\mathrm{C} 2267$ & 7 & 0 & & Integral membrane family protein; At4g15610 \\
\hline $\mathrm{C} 2315$ & 5 & 3 & & Expressed protein; At lg70780 \\
\hline $\mathrm{C} 2318$ & 3 & 2 & & Ribosome associated membrane protein RAMP4; At lg27350 \\
\hline C2343 & 9 & 9 & & Novel gene \\
\hline $\mathrm{C} 2560$ & 6 & 1 & & Expressed protein; At3g27880个 \\
\hline C2591 & 6 & 1 & & Expressed protein (located in mitochondrion); At5g24600 \\
\hline C2682* & 4 & 2 & & $\mathrm{~N}$-methyl-D-aspartate receptor-associated protein; At4gI5470 \\
\hline $\mathrm{C} 2713$ & 4 & 1 & & Glycine-rich protein; At4g22740 \\
\hline $\mathrm{C} 2778$ & 12 & 7 & & Zinc finger (ANI-like) family (DNA and zinc ion binding); At3g52800个 \\
\hline C2806 & 8 & 2 & & C2 domain-containing protein; At lg22610 \\
\hline C3094 & 3 & 2 & & Reticulon family protein (located in ER and mitochondrion); At3g $10260 \downarrow$ \\
\hline \multicolumn{5}{|c|}{ Cell homeostasis (GO:0019725) } \\
\hline C2265 & 91 & 38 & EI; E2; E4 & Metallothionein-like protein; At5g02380 \\
\hline C2202* & 5 & 1 & & Metallothionein-like protein; NSM ${ }^{4}$ \\
\hline \multicolumn{5}{|c|}{ Cell organization and biogenesis (GO:00 I6043) } \\
\hline C734 & 17 & 9 & E2; E4 & Proline-rich/extensin family; At2g27380 \\
\hline $\mathrm{C} 1240$ & 62 & 20 & $\mathrm{EI} ; \mathrm{E} 2 ; \mathrm{E} 4$ & Proline-rich/extensin family; At Ig54215 \\
\hline C2494* & 10 & 3 & E2 & Actin-depolymerizing factor 4; At5g59890 \\
\hline C2831 & 20 & 6 & $\mathrm{EI} ; \mathrm{E} 2 ; \mathrm{E} 4$ & Leucine-rich repeat/extensin family; At4g I 3340个 \\
\hline C304I & 12 & 5 & $\mathrm{E} 2 ; \mathrm{E} 4$ & Leucine-rich repeat/extensin family; At4g I 3340个 \\
\hline C831 & 4 & 2 & & BONI-associated protein (BAP2); At2g45760个 \\
\hline $\mathrm{Cl} 062$ & 4 & 1 & & Invertase/pectin methylesterase inhibitor family; At5g62360个 \\
\hline C2060 & 7 & 3 & & Expansin family; At4g38400个 \\
\hline C2086* & 6 & I & & Arabinogalactan-protein; At5g64310 \\
\hline C2073 & 6 & 2 & & Zinc finger protein (CYOI); At3gl 9220 \\
\hline C2574 & 7 & 3 & & Invertase/pectin methylesterase inhibitor family; At2g01610 \\
\hline C2762* & 4 & I & & Profilin 4; At2g 19770 \\
\hline C28I5 & 4 & I & & Phytochelatin synthetase; At4g16120 \\
\hline \multicolumn{5}{|c|}{ Cellular protein metabolism (GO:0044267) } \\
\hline C228* & 112 & 51 & EI; E2; E4 & DJ-I family protein/protease-related; At3g02720 $\downarrow$ \\
\hline C379* & 50 & 21 & $\mathrm{EI} ; \mathrm{E} 2 ; \mathrm{E} 4$ & DJ-I family protein/protease-related; At3g02720 $\downarrow$ \\
\hline $\mathrm{Cl} 1027^{*}$ & 47 & 46 & $\mathrm{EI} ; \mathrm{E} 2 ; \mathrm{E} 4$ & Heat shock cognate 70 kDa protein I; At5g02500 \\
\hline $\mathrm{Cl} 660$ & 51 & 25 & $\mathrm{EI} ; \mathrm{E} 2 ; \mathrm{E} 4$ & Cysteine proteinase inhibitor-related; At2g3 I 980 $\downarrow$ \\
\hline C2099* & 13 & 1 & $\mathrm{EI} ; \mathrm{E} 2 ; \mathrm{E} 4$ & DJ-I family protein/protease-related; At3g02720 $\downarrow$ \\
\hline C2436 & 17 & 3 & $\mathrm{EI} ; \mathrm{E} 2 ; \mathrm{E} 4$ & Rhomboid family protein; At Ig63120 \\
\hline C27I5 & 41 & 21 & $\mathrm{EI} ; \mathrm{E} 2 ; \mathrm{E} 4$ & Luminal binding protein I (BiP-I); At5g28540 \\
\hline C2066* & 3 & 2 & & 60 S ribosomal protein L23A; At3g55280个 \\
\hline \multicolumn{5}{|c|}{ Cellular protein metabolism (GO:0044267) } \\
\hline C2072* & 6 & 2 & & DNAJ heat shock protein; At3g44II0 \\
\hline $\mathrm{C} 2217^{*}$ & 7 & 3 & & $20 S$ proteasome beta subunit $A ; A t 4 g 31300$ \\
\hline C2308* & 9 & 0 & & Heat shock protein 70; At3g I 2580 $\downarrow$ \\
\hline C2345* & 4 & 2 & & Ubiquitin carrier protein E2; At2g02760 \\
\hline C2364 & 5 & 2 & & Phosphatase-related (SGTIB); At4g I I 260 \\
\hline $\mathrm{C} 2388$ & 5 & 3 & & F-box family protein (AtSKP2;2); At l g77000 \\
\hline
\end{tabular}


Table 2: Putative function of 164 genes preferentially expressed in cold stored peach fruits. (Continued)

\begin{tabular}{|c|c|c|c|c|}
\hline C2593 & 4 & $T$ & & C3HC4-type RING finger family protein; At I g26800 $\downarrow$ \\
\hline C2597 & 6 & 2 & & $26 \mathrm{~S}$ proteasome regulatory subunit S3; At Ig20200 \\
\hline C2691 & 7 & 6 & & C3HC4-type RING finger family protein; At5g476I0 \\
\hline C2360 & 10 & 7 & & Structural constituent of ribosome; At5gl5260 \\
\hline C2735 & 9 & 4 & & 40S ribosomal protein S9; At5g39850 \\
\hline C3022 & 6 & 2 & & Translation initiation factor IF5; At Ig36730 \\
\hline C305I* & 5 & 2 & & DJ-I family protein/protease-related; At3g02720 $\downarrow$ \\
\hline C3520 & 4 & I & & 60 S ribosomal protein L36; At3g53740 \\
\hline C355I* & II & 4 & & Cysteine proteinase inhibitor; At3g|2490个 \\
\hline C3656 & 6 & 4 & & 40S ribosomal protein S26; At3g56340 \\
\hline C4I3I & 3 & 2 & & C3HC4-type RING finger family protein; At5g48655 \\
\hline \multicolumn{5}{|c|}{ Development (GO:0007275) } \\
\hline $\mathrm{C} 2802$ & 10 & 2 & El & Senescence-associated protein; AtI g78020 $\downarrow$ \\
\hline C2919 & 10 & I & $\mathrm{EI} ; \mathrm{E} 2$ & Senescence-associated protein; At5g20700 \\
\hline $\mathrm{ClII3}$ & 6 & 3 & & Auxin-responsive protein; At3g25290 $\downarrow$ \\
\hline C3887* & 4 & I & & Maternal effect embryo arrest 60; At5g05950 \\
\hline C3942 & 6 & 4 & & SIAMESE, cyclin binding protein; At5g04470 $\downarrow$ \\
\hline C2457 & 6 & 0 & & Nodulin MtN3 family protein; At5g I3 I $70 \uparrow$ \\
\hline \multicolumn{5}{|c|}{ Generation of precursor metabolites and energy (GO:000609I) } \\
\hline $\mathrm{C} 2304$ & 7 & 1 & & NADH dehydrogenase; At4g05020个 \\
\hline $\mathrm{C} 2541$ & 8 & i & & Uclacyanin I; At2g32300 $\downarrow$ \\
\hline C2552 & 5 & 0 & & Flavin-containing monooxygenase family protein; At I g489 $10 \uparrow$ \\
\hline \multicolumn{5}{|c|}{ Metabolism (GO:0008I52)3 } \\
\hline $\mathrm{C} 1017$ & 15 & 9 & E2 & Xyloglucan endotransglycosylase; At4g258 I0 $\downarrow$ (carbohydrate) \\
\hline $\mathrm{C} 1258^{*}$ & 19 & 2 & EI; E2; E4 & Phosphoesterase family protein; At3g03520 $\downarrow$ (phospholipid) \\
\hline C2373 & 15 & 8 & E2; E4 & $\beta$-alanine-pyruvate aminotransferase; At2g38400 $\downarrow$ (amino acid) \\
\hline C2397* & 27 & 9 & $\mathrm{EI} ; \mathrm{E} 2 ; \mathrm{E} 4$ & S-adenosylmethionine decarboxylase; At3g02470 (polyamine) \\
\hline C2554* & 17 & 3 & $\mathrm{EI} ; \mathrm{E} 2 ; \mathrm{E} 4$ & UDP-glucoronosyl/UDP-glucosyl transferase; At5g65550 (anthocyanin) \\
\hline C2957 & 11 & 0 & EI; E2; E4 & Glycosyl hydrolase family 3; At5g49360 $\downarrow$ (carbohydrate) \\
\hline $\mathrm{C} 2669$ & 61 & 28 & EI; E2; E4 & Phosphoserine aminotransferase; At4g35630 (amino acid) \\
\hline C656 & 4 & 3 & & Nucleoside diphosphate kinase 3; At4gl I0I0 (nucleotide) \\
\hline $\mathrm{C} 821 *$ & 4 & 1 & & UDP-glucoronosyl/UDP-glucosyl transferase; At5g49690个 (anthocyanin) \\
\hline C926* & 7 & 6 & & (I-4)- $\beta$-mannan endohydrolase; At5g66460 $\uparrow$ (carbohydrate) \\
\hline $\mathrm{C} 1000^{*}$ & 8 & 2 & & Alkaline alpha galactosidase; At lg55740 (carbohydrate) \\
\hline $\mathrm{Cl} 693$ & 9 & 3 & & Haloacid dehalogenase-like hydrolase; At5g02230 $\downarrow$ \\
\hline $\mathrm{C} 1943$ & 4 & 3 & & 2-oxoglutarate-dependent dioxygenase; At Ig06620 (ethylene) \\
\hline $\mathrm{C} 2424$ & 5 & 0 & & $\beta$-amylase; At4g I 7090个 (starch) \\
\hline C2495 & 8 & I & & Cinnamoyl-CoA reductase; At4g30470 (lignin) \\
\hline $\mathrm{C} 2522$ & 11 & 8 & & Glycosyl hydrolase family 5; At I g I 3 | $30 \uparrow$ (carbohydrate) \\
\hline $\mathrm{C} 2569$ & 7 & I & & Short-chain dehydrogenase/reductase family; At3g6 I 220 $\downarrow$ \\
\hline $\mathrm{C} 2602$ & 5 & 0 & & Short-chain dehydrogenase/reductase family; At4g|3250 \\
\hline $\mathrm{C} 2610$ & 5 & 0 & & Galactinol synthase; At3g28340个 (carbohydrate) \\
\hline $\mathrm{C} 2222$ & 6 & 0 & & Carboxyesterase 5; At I g49660 $\downarrow$ \\
\hline $\mathrm{C} 2635$ & 6 & 4 & & GNSI/SUR4 membrane family protein; At4g36830 (fatty acid) \\
\hline $\mathrm{C} 2705$ & 7 & 4 & & DSBA oxidoreductase family protein; At5g38900 (organic acid) \\
\hline C669 & 4 & 2 & & Dehydrogenase; At5g 10730 \\
\hline C2936 & 4 & I & & Pyruvate decarboxylase; At5gl7380 (glycolisis) \\
\hline C2940 & 4 & 1 & & Farnesyl pyrophosphate synthetase I; At5g47770 (lipid) \\
\hline C2976 & 6 & i & & Aminoalcoholphosphotransferase; At IgI3560 (phospholipid) \\
\hline $\mathrm{C} 3047^{*}$ & 7 & 4 & & Dienelactone hydrolase; At3g23600 (alkene) \\
\hline \multicolumn{5}{|c|}{ Metabolism (GO:0008I52)3 } \\
\hline C3058* & 5 & $\hat{I}$ & & Cellulose synthase; At4g39350 (cellulose) \\
\hline C3152 & 8 & 3 & & Purple acid phosphatase; At3g52820 (phosphate) \\
\hline C3225 & 4 & I & & Acyl-activating enzyme 12; At Ig65890 (phospholipid) \\
\hline $\mathrm{C} 4 \mathrm{I} 27$ & 6 & 2 & & $\Omega$-3fatty acid desaturase; At5g05580 (fatty acid) \\
\hline $\mathrm{C} 86$ & 6 & 3 & & Embryo-abundant protein; At2g41380个 \\
\hline C677 & 4 & 2 & & Cyclic phosphodiesterase; At4gI8930 (RNA) \\
\hline $\mathrm{C} 802$ & 4 & 3 & & RNA recognition motif-containing protein; At5g04600 (RNA) \\
\hline $\mathrm{C} 2798$ & 3 & 2 & & Small nuclear ribonucleoprotein G; At2g23930 $\uparrow$ (RNA) \\
\hline \multicolumn{5}{|c|}{ Response to stress (GO:0006950) } \\
\hline C30 & 57 & 27 & EI; E2; E4 & Cold acclimation WCOR4I3-like protein; At3g50830 \\
\hline $\mathrm{C} 254$ & 71 & 10 & $\mathrm{EI} ; \mathrm{E} 2 ; \mathrm{E} 4$ & Dehydrin Xero2; At3g50970 $\uparrow$ \\
\hline C $304 *$ & 189 & 124 & EI; E2; E4 & Type II dehydrin SKII; (ERDI4) AtIg76I80个 \\
\hline C910 & 126 & 38 & $\mathrm{EI} ; \mathrm{E} 2 ; \mathrm{E} 4$ & Class III acidic endochitinase; At5g24090 \\
\hline $\mathrm{Cl} 479$ & 96 & 25 & $\mathrm{EI} ; \mathrm{E} 2 ; \mathrm{E} 4$ & Harpin inducing protein; At5g06320个 \\
\hline $\mathrm{Cl} 708$ & 30 & 12 & $\mathrm{EI} ; \mathrm{E} 2 ; \mathrm{E} 4$ & Thaumatin-like protein; At I g20030 \\
\hline $\mathrm{C} 2|3|$ & 65 & 2 & $\mathrm{EI} ; \mathrm{E} 2 ; \mathrm{E} 4$ & Class lb basic endochitinase; At3g I 2500个 \\
\hline
\end{tabular}


Table 2: Putative function of 164 genes preferentially expressed in cold stored peach fruits. (Continued)

\begin{tabular}{|c|c|c|c|c|}
\hline C2177 & 15 & 4 & $\mathrm{EI} ; \mathrm{E} 4$ & Thaumatin-like protein; AtIg20030 $\uparrow$ \\
\hline $\mathrm{C} 2317$ & 67 & 6 & EI; E2; E4 & Thaumatin-like protein; At I g20030 $\uparrow$ \\
\hline C25I4* & 20 & 15 & E2 & Glutathione peroxidase; At4g I I600个 \\
\hline C2528 & 22 & 7 & $\mathrm{EI} ; \mathrm{E} 2 ; \mathrm{E} 4$ & Hevein-like protein; At3g04720 $\downarrow$ \\
\hline C2655* & 10 & 6 & E4 & DREPP plasma membrane polypeptide; At4g20260 \\
\hline C2988* & 37 & 6 & $\mathrm{EI} ; \mathrm{E} 2 ; \mathrm{E} 4$ & Polygalacturonase inhibiting protein; At5g06860个 \\
\hline C2473* & 10 & 0 & $\mathrm{EI} ; \mathrm{E} 2 ; \mathrm{E} 4$ & Major allergen Pru P I; At Ig24020 \\
\hline C2147 & 8 & 0 & & Thaumatin-like protein; AtIg20030个 \\
\hline C244I & 8 & I & & Class IV chitinase; At3g54420 \\
\hline $\mathrm{C} 2507$ & 5 & 2 & & Pyridoxine biosynthesis protein; At5g0I410 \\
\hline $\mathrm{C} 2556$ & 5 & 0 & & 4-aminobutyrate aminotransferase; At3g22200 \\
\hline $\mathrm{C} 2578$ & 3 & 2 & & Aldehyde dehydrogenase; Atlg44170 \\
\hline C2926 & 7 & 2 & & Wounding stress inducimg protein; At4g24220 \\
\hline C3613* & 3 & 2 & & Harpin inducing protein; At3gII660 \\
\hline Cl889* & 5 & 4 & & Major allergen Pru p I; At Ig24020 \\
\hline C3858* & 4 & 2 & & Late embryogenesis abundant protein 3; At4g02380个 \\
\hline \multicolumn{5}{|c|}{ Signal transduction (GO:0007/65) } \\
\hline C8I5 & 9 & 1 & & Leucine-rich repeat family protein; At3g49750 \\
\hline $\mathrm{Cl} 192 *$ & 6 & 5 & & CBL-interacting protein kinase 12 ; At4g $18700 \uparrow$ \\
\hline $\mathrm{C} 2205$ & 5 & 4 & & Ser/Thr kinase; At2g47060 $\downarrow$ \\
\hline $\mathrm{C} 23 / 2^{*}$ & 8 & 3 & & Touch-responsive/calmodulin-related protein 3; At2g4I I00 $\downarrow$ \\
\hline C2430* & 6 & 6 & & Remorin family protein; At5g23750 $\downarrow$ \\
\hline $\mathrm{C} 2548$ & 10 & 6 & & Fringe-related protein; At4g00300 \\
\hline C2829* & 3 & 2 & & Protein kinase, $4 \mathrm{IK}$; At5g66880 $\downarrow$ \\
\hline C2853 & 5 & 3 & & GTP-binding protein Rab2; At4g17।70 \\
\hline C3690* & 10 & 8 & & Ser/Thr kinase; At4g40010 \\
\hline \multicolumn{5}{|c|}{ Transcription (GO:0006350) } \\
\hline C452 & 4 & 2 & & Myb family; At5g45420 \\
\hline $\mathrm{C} 2742 *$ & 5 & I & & DREB subfamily A-6; At I g78080 $\downarrow$ \\
\hline C3420* & 8 & 4 & & MADS-box protein (AGL9); At lg24260 \\
\hline $\mathrm{C} 3812$ & 3 & 2 & & WRKY family; At4g3 I550 $\uparrow$ \\
\hline \multicolumn{5}{|c|}{ Transport (GO:00068I0) } \\
\hline C716 & 13 & 5 & E2; E4 & Proton-dependent oligopeptide transport family; At5g62680 $\downarrow$ \\
\hline $\mathrm{Cl} 846$ & 15 & 10 & $\mathrm{E} 4$ & Auxin efflux carrier family protein; At2g I 7500 $\downarrow$ \\
\hline C2091 & 18 & 0 & EI; E2; E4 & Protease inhibitor/seed storage/lipid transfer family; At lg62790 \\
\hline $\mathrm{Cl} 63$ & 4 & I & & Vesicle-associated membrane protein; At lg08820 \\
\hline C208 & 9 & 2 & & GTP-binding secretory factor SAR IA; At4g02080 \\
\hline $\mathrm{C} 235$ & 5 & 4 & & Sugar transporter; At I g54730 $\downarrow$ \\
\hline C484 & 11 & 6 & & Porin; At5g67500 \\
\hline $\mathrm{C} 1526$ & 5 & 4 & & emp24/gp25L/p24 protein; At3g22845 \\
\hline \multicolumn{5}{|c|}{ Transport (G0:00068I0) } \\
\hline C2062 & 3 & 2 & & Ripening-responsive protein; At lg47530 \\
\hline $\mathrm{C} 2236$ & 3 & 2 & & Ras-related GTP-binding protein; At4g35860 \\
\hline $\mathrm{C} 2476$ & 9 & 1 & & Bet I gene family; At4g I 4450个 \\
\hline $\mathrm{C} 2679$ & 5 & 0 & & Sulfate transporter STI; At3g5 I 895 $\uparrow$ \\
\hline C3063 & 4 & 2 & & Amino acid carrier; At I g77380 $\uparrow$ \\
\hline C3066 & 4 & I & & Sulfate transporter; At3gl5990 \\
\hline C3099 & 3 & 2 & & Ras-related GTP-binding protein; At Ig52280 \\
\hline
\end{tabular}

I Statistically significant cold-induced contigs detected with the Audic and Claverie test $(p<0.01)$ vs. EI, E2 or E4 cDNA libraries. The column shows the cDNA library with differences to E3.

2The column described the locus identifier (id) of the Arabidopsis most similar protein. The locus ids with $\uparrow$ [37] are the Arabidopsis cold response genes similarly up-regulated; the locus ids with $\downarrow[3 I$ ] are the genes with opposite response, down-regulated in Arabidopsis (ColdArrayDB; http:/l cold.stanford.edu/cgi-bin/data.cgi).

${ }^{3}$ Between parentheses: the principal subcategory of the biological process "metabolism" associated to the annotation. ${ }^{4} \mathrm{NSM}$ : Not significant match $\left(E\right.$ value $<10^{-10}$ ) with $A$. thaliana sequences.

* Contigs that shown significant sequence homology (e value $>10^{-10}$ ) with contigs from others hierarchical clusters. 


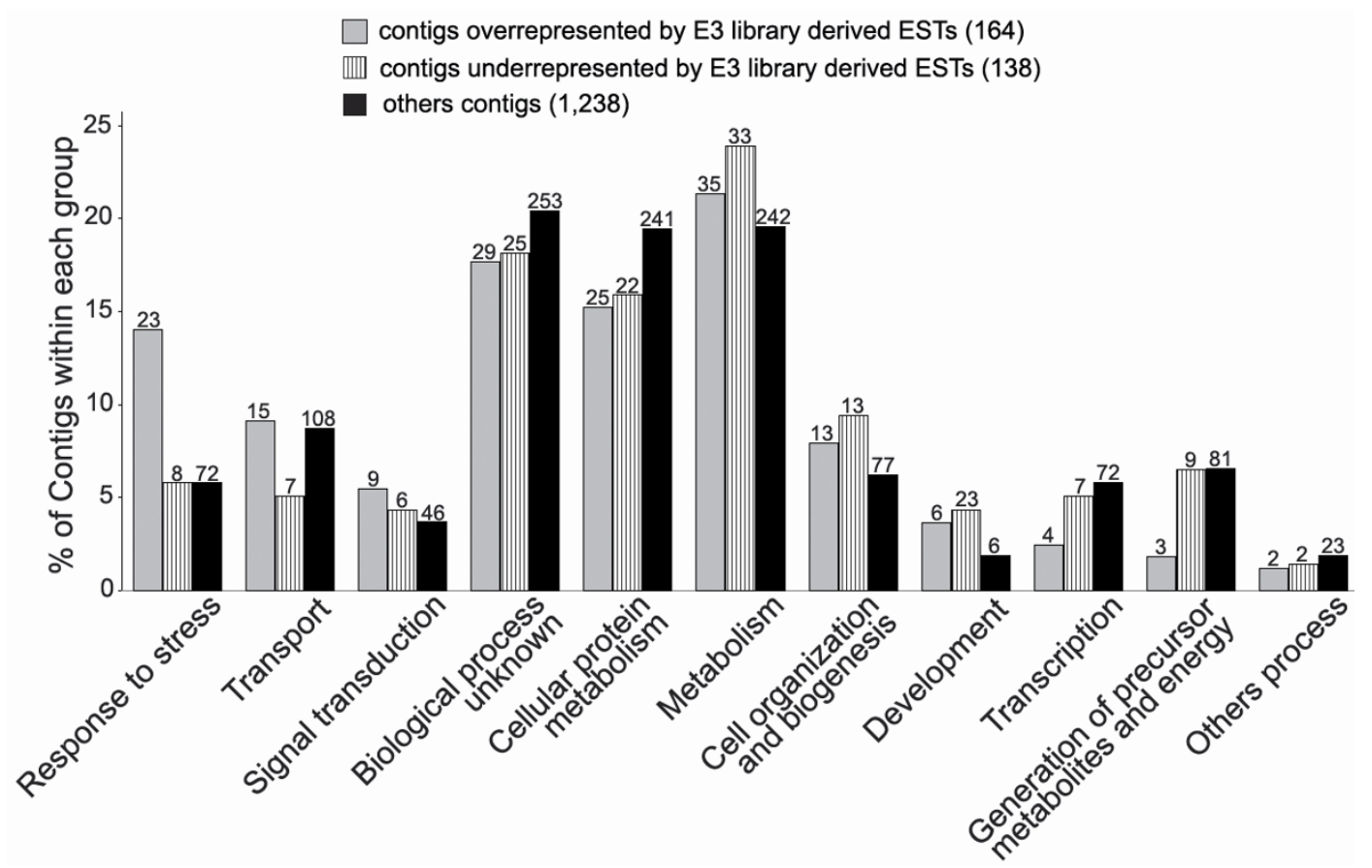

Figure I

Annotation frequency comparison of cold-induced, cold-repressed or unrelated to cold-induction contigs. The frequency of contigs that are associated with a specific Gene Ontology are expressed as the percentage of the total annotations for each analyzed group (I64 for the cold-induced, I 38 for the cold-repressed and I,238 for unrelated to cold-induction). The numbers of contigs in each group, belonging to each biological process classification, are show at the top of each bar. The category "others process" are: cell adhesion (GO: 0007I55, I contig); cell communication (GO: 0007I54, I contig); cell cycle (GO: 0007049, 5 contigs); cell death (GO: 00082 I 9, I contig); cell homeostasis (GO: 00I9725, 4 contigs); organism physiological process (GO: 0050874; I contig); regulation of GTPase activity (GO: 0043087; I contig); response to stimulus (GO: 0050896; 10 contigs) and viral life cycle (GO: 0016032 ; I contig).

stored fruits, whereas the Pplox1 gene increased expression in woolly fruits rather than cold-stored fruits.

Identification of conserved motifs in the promoters of coldinducible genes Ppbecl, Ppxero 2 and Ppthal

We cloned 826 bp, 1,348 bp and 1,559 bp fragments corresponding to the regions upstream of the translation start codons of Ppbec1, Ppxero2 and Pptha1, respectively. The sequences of these promoter regions as well as the cDNA of their corresponding genes are shown in the Additional Files 2, 3 and 4 .

The high sequence identity between the Ppxero2 contig with the coding region of Ppdhn1[30] was also observed within the promoter sequences of these two genes. Only one nucleotide difference at position -469 was found, suggesting that Ppxero2 and Ppdhn1 may be the same gene (Additional File 3). However, the promoter isolated in this work is about 230 bp longer (at the 5' end) than the previously published promoter [30].
Cis-element regulatory motifs related to cold gene expression regulation such as ABRE [13], MYCR [31,32], MYBR $[31,33]$ and DRE/CRT [34] were identified in all three promoters of these cold-inducible genes (Figure 3 ). In addition, three statistically significant predicted motifs were present in the promoters of these cold-inducible genes (TACGTSGS, TGTGTGYS and CTAGAASY (Figure 3). These motifs were not found in the Pplox1 promoter identified in this work (Additional File 5).

\section{Cold-induced Ppbecl and Ppxero2 promoters in transiently transformed peach fruits and stably transformed Arabidopsis}

Transient transformation assays of peach fruits revealed that all three cloned promoters (pBIPpbec1, pBIPxero2 and pBIPptha1) were able to activate GUS (uidA) expression (Figure 4). However, only the pBIPpbec1 and pBIPxero2 promoter constructs showed cold-inducible increases in GUS activity (Figure 4). The pBIPtha1 construct was expressed at both $20^{\circ} \mathrm{C}$ and $4^{\circ} \mathrm{C}$. Comparable 

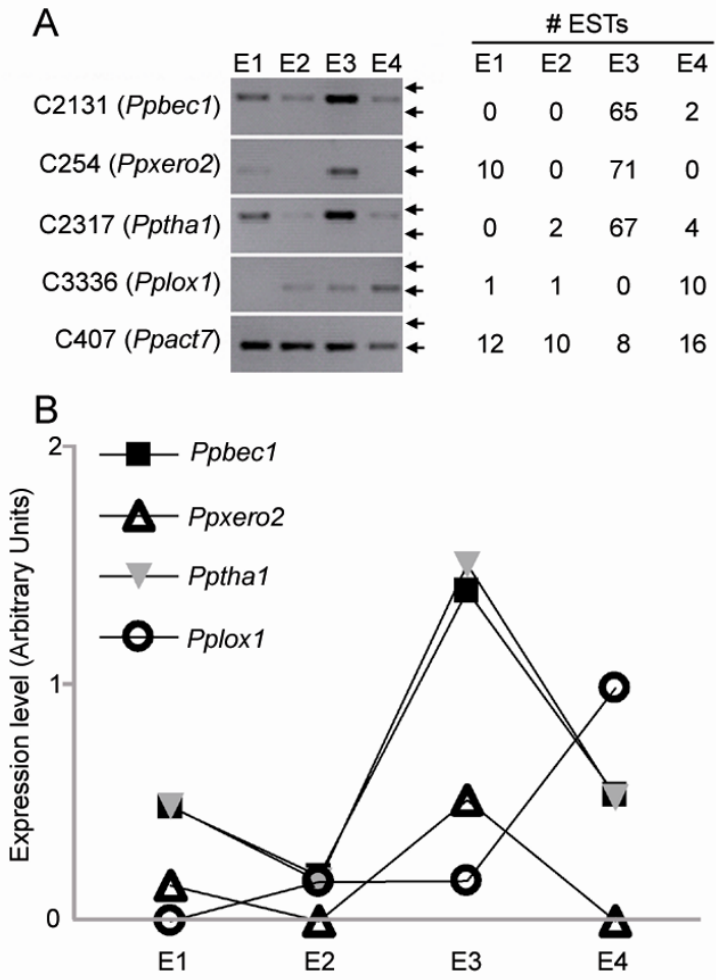

Figure 2

Evaluation of the accuracy of the predicted expression patterns of selected genes by RT-PCR. (A) RTPCR analysis of RNA expression of three cold-induced genes: Ppbecl, Ppxero2, and Ppthal under different post-harvest conditions. These post-harvest conditions include: fruits processed in a packing plant (EI: non-ripe; no long term cold storage); packing followed by a shelf-life at $20^{\circ} \mathrm{C}$ for $2-6$ days (E2: Ripe; no long term cold storage; juicy fruits); packing followed by cold storage at $4^{\circ} \mathrm{C}$ for $2 \mathrm{I}$ days (E3: non-ripe; long term cold storage) and packing followed by cold storage at $4^{\circ} \mathrm{C}$ for 21 days and shelf-life at $20^{\circ} \mathrm{C}$ for 2-6 days (E4: Ripe; long term cold storage; woolly fruits). The expression level of Pplox I was analyzed as a control for genes that do not express preferentially in cold stored fruits (E3). Ppact7 was analyzed as a control for genes that do not significantly change expression levels between the four post-harvest conditions analyzed. The two arrows associated with each gel represent $500 \mathrm{bp}$ (upper) and $300 \mathrm{bp}$ (lower). The number of ESTs associated with each contig and library source is indicated. (B) Densitometry quantification of the expression level obtained by RT-PCR, the figure shows the bands intensities for each gene relative to Ppact7 intensity.

results were seen in fruits from three different peach varieties (data not shown).

Similar results were seen when these promoter-GUS constructs were analyzed in stably transformed Arabidopsis.
All three constructs were able to activate GUS expression, but only the Ppbec1 and Ppxero2 promoters (pBIPpbec1 and pBIPxero2, respectively) induced expression in response to cold (Figure 5). As observed with the fruit transient transformation assays, the Pptha1 promoter (pBIPtha1) expressed GUS under all conditions analyzed.

\section{Discussion and Conclusion}

Digital expression analyses of EST datasets have permitted us to identify a large diversity of cold-inducible genes in peach fruits, three of which were chosen for further analyses (Ppbec1, Ppxero2 y Pptha1). Both digital expression analyses and RT-PCR suggest that the Ppbec1, Ppxero 2 and Pptha1 are cold-inducible genes. The promoters of these cold-inducible genes were isolated and characterized using both transient transformation assays in peach fruits and stable transformation in Arabidopsis. These analyses have revealed that the isolated Ppbec1 and Ppxero2 promoters are cold-inducible promoters, whereas the isolated Pptha1 promoter was not cold-inducible. These results, therefore, demonstrate that the isolated Ppbec1 and Ppxero2 promoters are sufficient for cold-induced gene expression. Furthermore, these results suggest that there is a conserved heterologous cold-inducible regulation of these promoters in peach and Arabidopsis.

Plants respond to cold temperatures by modifying the transcription and translation levels of hundreds of genes $[35,36]$. These acute molecular changes are related to plant cell physiological and biochemical modifications (cold acclimation) that lead to stress tolerance and cold adaptation (a chronic response). In peach fruits, cold temperatures induce chilling injury, possibly due to global transcriptome changes [37]. With the exception of studies in the model organism A. thaliana [4] and work published recently $[17,38]$, little is known about the peach global transcriptional response to cold. Using the Pearson correlation coefficient, we analyze the coordinated gene expression of 1,402 contigs. This analysis revealed 164 genes preferentially expressed in peach fruits, of which digital expression analyses [18] revealed 45 of these genes (27\%) with statistically significant cold-induction. A large proportion of the contigs preferentially expressed at $4{ }^{\circ} \mathrm{C}$ (around $74 \%$ of the total) do not exhibited significant sequence homology (e-value $<\mathrm{e}^{-10}$ ) with the rest of the analyzed contigs (Table 2). This result could suggest that these contigs represent genes with non-redundant functions that will have a special importance during the exposure of the fruits to low temperatures.

Among the highly expressed genes in cold stored fruits, we found genes related to stress response in plants, including three dehydrins (C30, C254 and C304), three chitinases (C910, C2131 and C2441), four thaumatin-like proteins (C1708, C2177, C2317 and C2147), and polygalacturo- 
TACGTSGS, zscore: 12.13

TGTGTGYS, zcores: 9.34

* CTAGAASY, zscore: 7.79
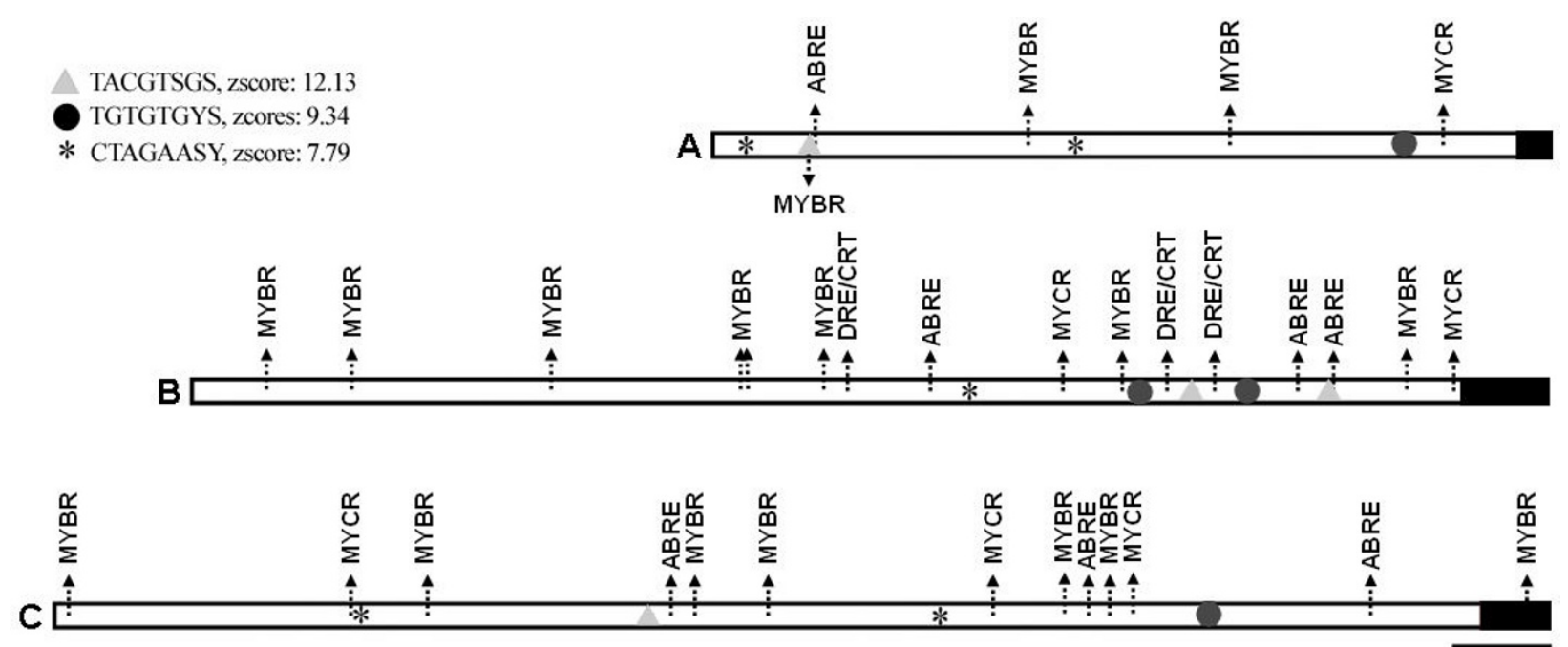

\section{Figure 3}

Putative cis-regulatory elements identified in Ppbecl, Ppxero2 and Ppthal promoter sequences. Topologies of the Ppbecl (A), Ppxero2 (B) and Ppthal (C) promoters are shown. The promoters are draw proportionally (the bar correspond to 100 bp). Boxed regions: predicted 5' UTR region. Black arrow shows the position of different cis-regulatory elements related to low temperature responses: ABRE, DRE/CRT, MYBR and MYCR. The putative cis-regulatory elements identified by the motif prediction program YMF3.0 are shown as grey triangle, black circle and asterisk. The sequences, the symbol and the significance score (Zscore) of the motifs, are shown in the upper left corner. The degenerate bases allowed in the motifs are $S$ (C or $\mathrm{G})$ and $\mathrm{Y}(\mathrm{C}$ or $\mathrm{T})$. Note: in order to ensure at the legibility of the figure, not all cis-elements are marked in (B) and (C). However, the complete sequences of these promoters are available in Additional Files 3 and 4.

A

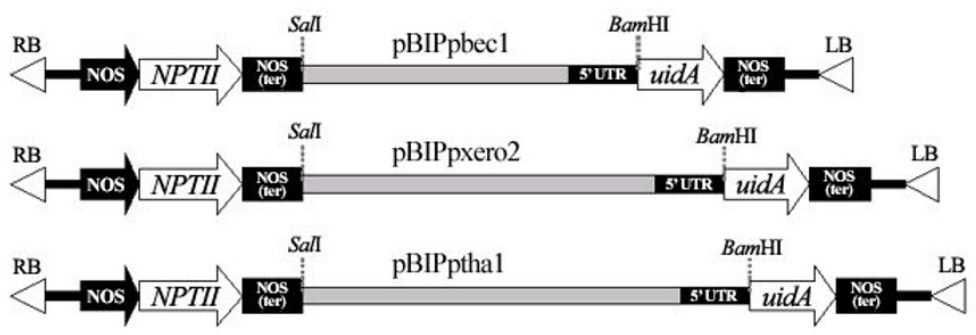

B

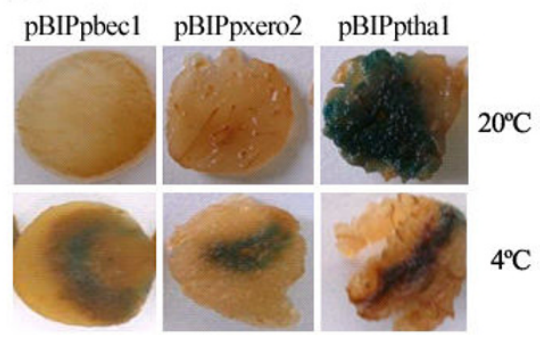

\section{Figure 4}

Cold-inducible peach Ppbecl and Ppxero2 promoters in transiently transformed peach fruits. (A) Structure of the binary vector constructs used for functional analysis of the Ppbecl, Ppxero2 and Ppthal promoter-uidA fusions. LB and RB: left and right T-DNA border. (B) Histochemical GUS staining of fruit slices from agro-infiltrated peaches stored at $20^{\circ} \mathrm{C}$ for 5 days post-inoculation or $4^{\circ} \mathrm{C}$ for 10 days. These images correspond to the transient transformation of $O^{\prime} H e n r y$ variety fruits. However, similar results were seen in all varieties assayed (data not shown). 

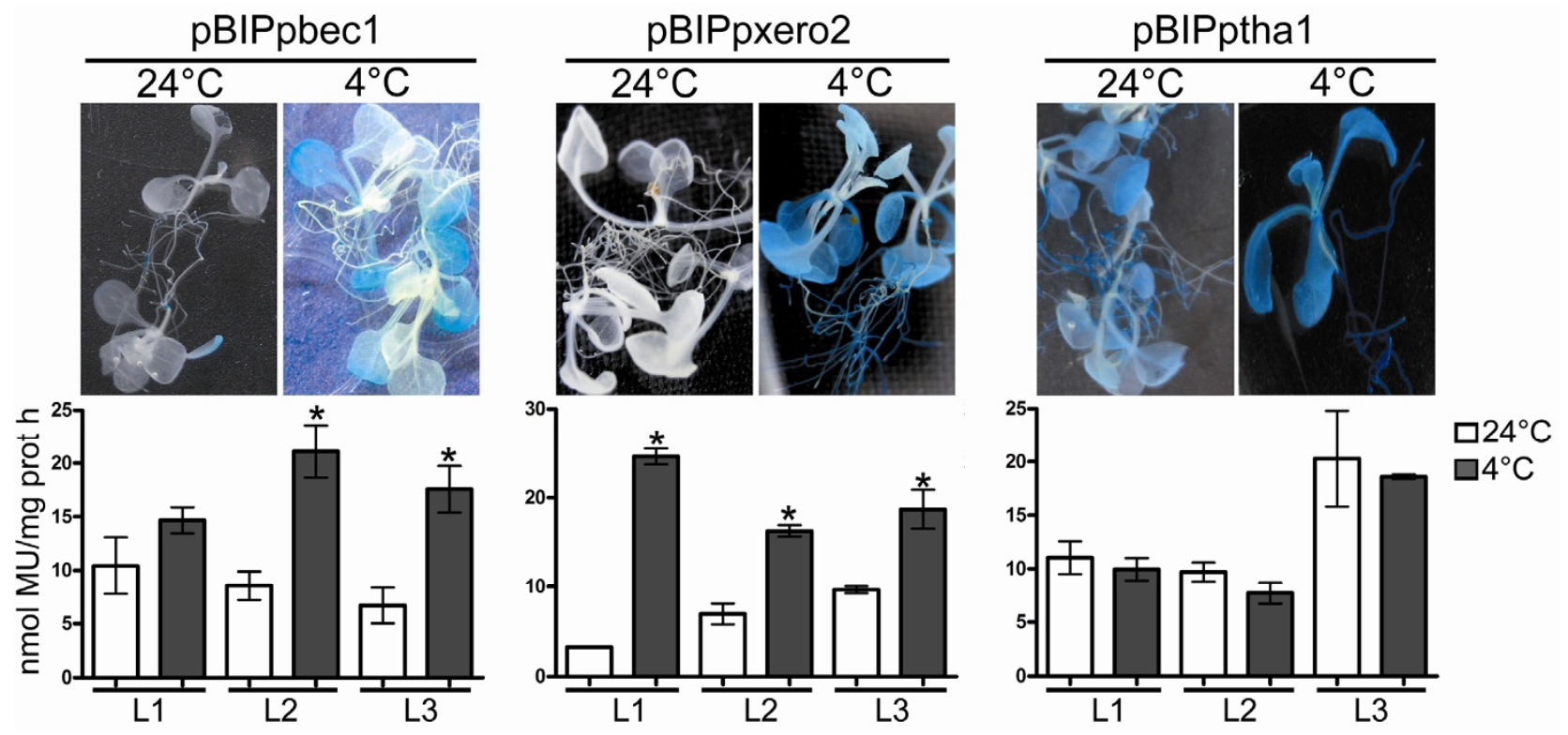

Figure 5

Conserved heterologous regulation of the cold-inducible peach Ppbecl and Ppxero2 promoters in transgenic Arabidopsis plants. The upper panel shows histochemical GUS staining of representative transgenic Arabidopsis lines carrying the Ppbecl promoter-uidA fusion, Ppxero2 promoter-uidA fusion and Ppthal promoter-uidA fusion. The lower panel shows the results of fluorometric GUS-assays of three independent Arabidopsis transgenic lines (LI, L2 and L3) containing the Ppbecl promoter-uidA fusion, Ppxero2 promoter-uidA fusion or Ppthal promoter-uidA fusion. Homozygous T3 plants were grown for 14 days in MS plates with $0.8 \%$ agar at $24^{\circ} \mathrm{C}$ (white bars) and then transfer to $4^{\circ} \mathrm{C}$ for 7 days (blacks bars). The asterisk above each bar represents those samples that have a statistically significant increase in GUS activity in the cold treated plants when compared to the untreated plants. Bars represent the mean \pm standard deviation, $n=5$. $t$-student $* \mathrm{p}<0.0 \mathrm{I}$.

nase inhibiting protein (C2988), similar to what was reported by Ogundiwin et al [38]. Dehydrins are hydrophilic proteins that belong to the subgroup D-11 of the LEA ("late-embryogenesis-abundant") proteins [39]. There is some evidence that suggests that dehydrins protect macromolecules such as membranes and proteins against the damages associated with water deficiency [4042 ]. In peach, these genes are induced during cold acclimation and in cold-stored fruits [30,38]. It has been observed that pathogenesis-related (PR) proteins such as chitinases and thaumatins are accumulated in the apoplastic space in winter rye during cold acclimation. These proteins also may have antifreeze properties that will protect the integrity of the plant cell avoiding the formation of ice $[43,44]$. It has also been observed that these types of proteins retain their enzymatic activity under low temperatures, and may form part of a general response mechanism associated with unfavorable conditions, by providing protection from opportunist pathogen attack whilst the plant is in a weakened state [45-47]. A similar role is shared by polygalacturonase inhibiting proteins in different plants models $[48,49]$.
We also found some genes related to protein folding and degradation, such as heat shock proteins, BiP-1 and DJ-1 family proteins (Table 2 ). These processes are very active when plants face low temperatures, chemical and oxidative stress. These proteins participate in the prevention and repair of damage produced by cold, through the stabilization of protein structure and the degradation of proteins that are not folded correctly $[50,51]$.

In this work we were interested in isolating and functionally characterizing promoters of cold-inducible peach genes. To date, only a few inducible promoters have been identified in crop plants. The Pptha1, Ppbec1 and Ppxero 2 genes were chosen for promoter cloning and characterization based on the up-regulation that these genes showed in the in silico analysis and RT-PCR. The promoter sequences of these genes contain several cis-regulatory elements such as DRE/CRT, ABRE, MYCR (MYC recognition site) and MYBR (MYB recognition site) [13,31-34] that are related to stress response, specifically to cold/dehydration. These cis-regulatory elements are conserved in several plant species [52]. The presence of these conserved 
motifs suggests that these promoters may respond to the cold. Using transient transformation in peach fruit we confirmed that the promoters isolated from Ppbec1 and Ppxero2 are induced during low temperature storage, but not at room temperature. On the other hand, the Pptha1 promoter is active under all the temperatures analyzed. This could indicate that the Pptha1 promoter sequence might not contain all the elements needed to regulate expression in a cold-inducible manner. Alternatively, the agro-infiltration technique may induce stress signals that will activate this promoter. However, this last possibility is not likely because the activation of the Pptha1 promoter at all analyzed temperatures is also seen in the stably transformed transgenic Arabidopsis plants. The promoters Ppbec1 and Ppxero2, however, are cold-induced both in Arabidopsis transgenic plants as well as transient expressing fruits, suggesting that the Ppbec1 and Ppxero2 promoters are cold-inducible peach promoters. The coldinducibility of these promoters in A. thaliana also suggests that this model plant may be used to functionally analyze peach cold-induced genes as well as their corresponding cis-elements and trans-acting factors.

The identification of these fruit tree cold-inducible promoters as well as the conserved heterologous regulation of these promoters in peach and Arabidopsis, demonstrates that these two transformation assays may be used to molecularly define the cis-elements and trans-acting regulatory factors that are associated with cold-responsive genes. By better understanding the regulatory mechanisms associated with cold-responsive genes, we may better understand the molecular differences and similarities between cold acclimation and chilling injury as well as the role these processes play in fruit tree growth and fruit quality.

\section{Authors' contributions}

AT: identified and cloned the promoters. AT, MS, LM and HS drafted the manuscript. AT and MS: performed the digital expression analysis. AM and AT: performed the construction of Arabidopsis transgenic plants as well as the transient assay. HS: conceived, supervised and participated in all the analysis. All authors read and approved the manuscript.

\section{Additional material}

\section{Additional file 1}

Identification of fruit cold-induced contigs using correlated expression analysis of peach ESTs. The data provided represents the co-expression analysis of differentially expressed genes. The contigs were clustered using the Pearson linear correlation coefficient.

Click here for file

[http://www.biomedcentral.com/content/supplementary/14712229-9-121-S1.DOC]

\section{Additional file 2}

Sequence of the Ppbec1 promoter and open reading frame. The data provided represents the sequences of the Ppbec1 promoter and open reading frame.

Click here for file

[http://www.biomedcentral.com/content/supplementary/1471-

2229-9-121-S2.DOC]

\section{Additional file 3}

Sequence of the Ppxero2 promoter and open reading frame. The data provided represents the sequences of the Ppxero 2 promoter and open reading frame.

Click here for file

[http://www.biomedcentral.com/content/supplementary/14712229-9-121-S3.DOC]

\section{Additional file 4}

Sequence of the Pptha1 promoter and open reading frame. The data provided represents the sequences of the Pptha1 promoter and open reading frame.

Click here for file

[http://www.biomedcentral.com/content/supplementary/14712229-9-121-S4.DOC]

\section{Additional file 5}

Sequence of the Pplox1 promoter and open reading frame. The data provided represents the sequences of the Pplox 1 promoter and open reading frame.

Click here for file

[http://www.biomedcentral.com/content/supplementary/14712229-9-121-S5.DOC]

\section{Acknowledgements}

This work was supported by ICM P06-065-F; FDI G02PI00I (Chilean Genome Initiative) with funding from the Chilean government as well as ASOEX (Asociación de Exportadores de Chile A.G.), FDF (Fundación para el Desarrollo Frutícola) and Fundación Chile; Proyecto Consorcio BIOFRUTALES S.A.; PBCT RII and CONICYT Fellowship D-2I080654 to AM.

\section{References}

I. Thomashow MF: So what's new in the field of plant cold acclimation? Lots! Plant Physiol 200I, I 25(I):89-93.

2. Sharma P, Sharma N, Deswal R: The molecular biology of the low-temperature response in plants. Bioessays 2005, 27(10): 1048-1059.

3. Thomashow MF: PLANT COLD ACCLIMATION: Freezing Tolerance Genes and Regulatory Mechanisms. Annu Rev Plant Physiol Plant Mol Biol 1999, 50:57I-599.

4. Zhu J, Dong $\mathrm{CH}$, Zhu JK: Interplay between cold-responsive gene regulation, metabolism and RNA processing during plant cold acclimation. Curr Opin Plant Biol 2007, 10(3):290-295.

5. Fowler S, Thomashow MF: Arabidopsis transcriptome profiling indicates that multiple regulatory pathways are activated during cold acclimation in addition to the CBF cold response pathway. Plant Cell 2002, I4(8): 1675-1690.

6. Mahajan S, Tuteja N: Cold, salinity and drought stresses: an overview. Arch Biochem Biophys 2005, 444(2): 139-158.

7. Crisosto C, Mitchell F, Ju Z: Susceptibility to chilling injury of peach, nectarine, and plum cultivars grown in California. HortScience 1999, 34:11116-1118.

8. Crisosto $\mathrm{CH}$, Mitchell FG, Johnson S: Factors in fresh market stone fruit quality. Postharvest News and Information 1995, 6(2): $|7-2|$. 
9. Retamales J, Cooper T, Streif J, Kania J: Preventing cold storage disorders in nectarines. J Hort Sci 1992, 67:619-626.

10. Bonetta $D$, McCourt $P$ : Genetic analysis of ABA signal transduction pathways. Trends in Plant Science 1998, 3(6):23I-235.

II. Kasuga M, Liu Q, Miura S, Yamaguchi-Shinozaki K, Shinozaki K: Improving plant drought, salt, and freezing tolerance by gene transfer of a single stress-inducible transcription factor. Nat Biotechnol 1999, 17(3):287-291.

12. Kyonoshin Maruyama YS, Mie Kasuga, Yusuke Ito, Motoaki Seki, Hideki Goda, Yukihisa Shimada, Shigeo Yoshida, Kazuo Shinozaki, Kazuko Yamaguchi-Shinozaki: Identification of cold-inducible downstream genes of the Arabidopsis DREB IA/CBF3 transcriptional factor using two microarray systems. The Plant Journal 2004, 38(6):982-993.

13. Yamaguchi-Shinozaki K, Shinozaki K: A novel cis-acting element in an Arabidopsis gene is involved in responsiveness to drought, low-temperature, or high-salt stress. Plant Cell 1994 , 6(2):25I-264.

14. Tittarelli A, Milla L, Vargas F, Morales A, Neupert C, Meisel LA, Salvo GH, Penaloza E, Munoz G, Corcuera LJ, et al.: Isolation and comparative analysis of the wheat TaPT2 promoter: identification in silico of new putative regulatory motifs conserved between monocots and dicots. J Exp Bot 2007, 58(10):2573-2582.

15. Spolaore S, Trainotti L, Casadoro G: A simple protocol for transient gene expression in ripe fleshy fruit mediated by Agrobacterium. J Exp Bot 200I, 52(357):845-850.

16. Ahmad M, Mirza B: An efficient protocol for transient transformation of intact fruit and transgene expression in Citrus. Plant Molecular Biology Reporter 2005, 23(4):4 I9-420.

17. Vizoso P, Meisel L, Tittarelli A, Latorre M, Saba J, Caroca R, Maldonado J, Cambiazo V, Campos-Vargas R, Gonzalez M, et al.: Comparative EST transcript profiling of peach fruits under different postharvest conditions reveals candidate genes associated with peach fruit quality. BMC Genomics 2009, 10:421

18. Audic S, Claverie JM: The significance of digital gene expression profiles. Genome Res 1997, 7(10):986-995.

19. Ewing RM, Ben Kahla A, Poirot O, Lopez F, Audic S, Claverie JM: Large-scale statistical analyses of rice ESTs reveal correlated patterns of gene expression. Genome Res 1999, 9(10):950-959.

20. Eisen MB, Spellman PT, Brown PO, Botstein D: Cluster analysis and display of genome-wide expression patterns. Proc Nat Acad Sci USA 1998, 95(25): | 4863-|4868.

21. Meisel L, Fonseca B, Gonzalez S, Baeza-Yates R, Cambiazo V, Campos $\mathrm{R}$, Gonzalez M, Orellana A, Retamales J, Silva $\mathrm{H}$ : A rapid and efficient method for purifying high quality total RNA from peaches (Prunus persica) for functional genomics analyses. Biol Res 2005, 38(I):83-88.

22. Manubens A, Lobos S, Jadue Y, Toro M, Messina R, Lladser M, Seelenfreund D: DNA Isolation and AFLP Fingerprinting of Nectarine and Peach Varieties (Prunus persica). Plant Molecular Biology Reporter 1999, 17(3):255-267.

23. Jefferson RA, Kavanagh TA, Bevan MW: GUS fusions: beta-glucuronidase as a sensitive and versatile gene fusion marker in higher plants. EMBO J 1987, 6(I3):390I-3907.

24. Higo K, Ugawa $Y$, Iwamoto M, Korenaga T: Plant cis-acting regulatory DNA elements (PLACE) database: 1999. Nucleic Acids Res 1999, 27(I):297-300.

25. Blanchette M, Sinha S: Separating real motifs from their artifacts. Bioinformatics 200I, I7(SuppI I):S30-38.

26. Sinha S, Tompa M: Discovery of novel transcription factor binding sites by statistical overrepresentation. Nucleic Acids Res 2002, 30(24):5549-5560.

27. Gonzalez J, Reyes F, Salas C, Santiag M, Codriansky Y, Coliheuque N, Silva H: Arabidopsis thaliana: a model host plant to study plant-pathogen interaction using Chilean field isolates of Botrytis cinerea. Biol Res 2006, 39(2):221-228.

28. Clough SJ, Bent AF: Floral dip: a simplified method for Agrobacterium-mediated transformation of Arabidopsis thaliana. Plant J 1998, 16(6):735-743.

29. Bradford MM: A rapid and sensitive method for the quantitation of microgram quantities of protein utilizing the principle of protein-dye binding. Anal Biochem 1976, 72:248-254

30. Wisniewski ME, Bassett CL, Renaut J, Farrell R Jr, Tworkoski T, Artlip TS: Differential regulation of two dehydrin genes from peach
(Prunus persica) by photoperiod, low temperature and water deficit. Tree Physiol 2006, 26(5):575-584.

31. Abe H, Urao T, Ito T, Seki M, Shinozaki K, Yamaguchi-Shinozaki K: Arabidopsis AtMYC2 (bHLH) and AtMYB2 (MYB) function as transcriptional activators in abscisic acid signaling. Plant Cell 2003, I5(I):63-78.

32. Chinnusamy V, Ohta M, Kanrar S, Lee BH, Hong X, Agarwal M, Zhu JK: ICEI: a regulator of cold-induced transcriptome and freezing tolerance in Arabidopsis. Genes Dev 2003, I 7(8): $1043-1054$

33. Solano R, Nieto C, Avila J, Canas L, Diaz I, Paz-Ares J: Dual DNA binding specificity of a petal epidermis-specific MYB transcription factor (MYB.Ph3) from Petunia hybrida. EMBO J 1995, 14(8): I773-1784.

34. Shinozaki K, Yamaguchi-Shinozaki K: Molecular responses to dehydration and low temperature: differences and cross-talk between two stress signaling pathways. Curr Opin Plant Biol 2000, 3(3):217-223.

35. Umezawa T, Fujita M, Fujita Y, Yamaguchi-Shinozaki K, Shinozaki K: Engineering drought tolerance in plants: discovering and tailoring genes to unlock the future. Curr Opin Biotechnol 2006, 17(2): I 13-122.

36. Yamaguchi-Shinozaki K, Shinozaki K: Organization of cis-acting regulatory elements in osmotic- and cold-stress-responsive promoters. Trends Plant Sci 2005, I 0(2):88-94.

37. Gonzalez-Aguero M, Pavez L, Ibanez F, Pacheco I, Campos-Vargas $R$, Meisel LA, Orellana A, Retamales J, Silva H, Gonzalez M, et al.: Identification of woolliness response genes in peach fruit after post-harvest treatments. JExp Bot 2008, 59(8):1973-1986.

38. Ogundiwin EA, Marti C, Forment J, Pons C, Granell A, Gradziel TM, Peace CP, Crisosto CH: Development of ChillPeach genomic tools and identification of cold-responsive genes in peach fruit. Plant Mol Biol 2008, 68(4-5):379-397.

39. Close TJ: Dehydrins: A commonalty in the response of plants to dehydration and low temperature. Physiologia Plantarum 1997, 100:291-296.

40. Koag MC, Fenton RD, Wilkens S, Close TJ: The binding of maize DHNI to lipid vesicles. Gain of structure and lipid specificity. Plant Physiol 2003, I 3 I(I):309-316.

4I. Rorat T: Plant dehydrins--tissue location, structure and function. Cell Mol Biol Lett 2006, I I (4):536-556.

42. Sanchez-Ballesta MT, Rodrigo MJ, Lafuente MT, Granell A, Zacarias L: Dehydrin from citrus, which confers in vitro dehydration and freezing protection activity, is constitutive and highly expressed in the flavedo of fruit but responsive to cold and water stress in leaves. J Agric Food Chem 2004, 52(7): 1950- 1957.

43. Hon WC, Griffith M, Mlynarz A, Kwok YC, Yang DS: Antifreeze proteins in winter rye are similar to pathogenesis-related proteins. Plant Physiol 1995, 109(3):879-889.

44. Yu XM, Griffith $M$, Wiseman $S B$ : Ethylene induces antifreeze activity in winter rye leaves. Plant Physiol 200I, I 26(3): $1232-1240$

45. Dani V, Simon WJ, Duranti M, Croy RR: Changes in the tobacco leaf apoplast proteome in response to salt stress. Proteomics 2005, 5(3):737-745

46. Diaz-Vivancos P, Rubio M, Mesonero V, Periago PM, Barcelo AR, Martinez-Gomez P, Hernandez JA: The apoplastic antioxidant system in Prunus: response to long-term plum pox virus infection. J Exp Bot 2006, 57( ( 4):38|3-3824.

47. Hiilovaara-Teijo M, Hannukkala A, Griffith M, Yu XM, PihakaskiMaunsbach K: Snow-mold-induced apoplastic proteins in winter rye leaves lack antifreeze activity. Plant Physiol 1999, I2I(2):665-674.

48. Meyer K, Keil M, Naldrett MJ: A leucine-rich repeat protein of carrot that exhibits antifreeze activity. FEBS Lett 1999, 447(2$3): 171-178$

49. Yao C Conway WS, Ren R, Smith D, Ross GS, Sams CE: Gene encoding polygalacturonase inhibitor in apple fruit is developmentally regulated and activated by wounding and fungal infection. Plant Mol Biol 1999, 39(6): | 23I-I24I.

50. Iba K: Acclimative response to temperature stress in higher plants: approaches of gene engineering for temperature tolerance. Annu Rev Plant Biol 2002, 53:225-245.

5I. Sabehat A, Lurie S, Weiss D: Expression of small heat-shock proteins at low temperatures. A possible role in protecting against chilling injuries. Plant Physiol 1998, I 17(2):65I-658. 
52. Chen WJ, Zhu T: Networks of transcription factors with roles in environmental stress response. Trends Plant Sci 2004, 9(12):59|-596.

Publish with Bio Med Central and every scientist can read your work free of charge

"BioMed Central will be the most significant development for disseminating the results of biomedical research in our lifetime. " Sir Paul Nurse, Cancer Research UK

Your research papers will be:

- available free of charge to the entire biomedical community

- peer reviewed and published immediately upon acceptance

- cited in PubMed and archived on PubMed Central

- yours - you keep the copyright

Submit your manuscript here:

http://www.biomedcentral.com/info/publishing_adv.asp
BioMedcentral 